\title{
Factors influencing Physicians' Detection of Cancer Patients' and relatives' Distress: Can a Communication Skills Training Program improve Physicians' Detection?
}

Isabelle Merckaert (M.A.) $)^{1}$, Yves Libert (Ph. D. $)^{2,3}$, Nicole Delvaux (Ph. D. $)^{1,4}$, Serge Marchal (M.A.) $)^{5}$, Jacques Boniver (M.D., Ph. D. $)^{6}$, Anne-Marie Etienne (Ph. D. $)^{7}$, Jean Klastersky (M.D., Ph. D. $)^{2}$, Christine Reynaert (M.D., Ph. D. $)^{8}$, Pierre Scalliet (M.D., Ph. D. $)^{9}$, JeanLouis Slachmuylder (M.A.) ${ }^{5}$, Darius Razavi (M.D., Ph. D.) $)^{1-2}$

${ }^{1}$ Unité de Recherche en Psychosomatique et Psycho-oncologie, Université Libre de Bruxelles, Bruxelles, Belgium; ${ }^{2}$ Service de Médecine Interne, Institut Jules Bordet, Université Libre de Bruxelles, Bruxelles, Belgium; ${ }^{3}$ Ressources Humaines, Institut Jules Bordet, Université Libre de Bruxelles, Bruxelles, Belgium; ${ }^{4}$ Service de Psychologie, Hôpital Universitaire Erasme, Université Libre de Bruxelles, Bruxelles, Belgium; ${ }^{5}$ C.A.M. (Centre d'aide aux mourants, Training and Research Group), Bruxelles, Belgium; ${ }^{6}$ Département des sciences précliniques

MI, Université de Liège, Liège, Belgium; ${ }^{7}$ Faculté de Psychologie et des Sciences de l'Education, Université de Liège, Liège, Belgium; ${ }^{8}$ Unité de Psychologie Médicale, Université Catholique de Louvain, Louvain-la-neuve, Belgium; ${ }^{9}$ Département de Médecine Interne, Université Catholique de Louvain, Louvain-la-neuve, Belgium.

\section{Correspondence should be sent to the following address:}

Darius Razavi, M.D., Ph.D.

Université Libre de Bruxelles

Av. F. Roosevelt, 50 - CP 191

B-1050 Bruxelles

Belgium

Phone: 003226504581 and 003226502631

Fax: 003226502209

E-mail: drazavi@ulb.ac.be

Running head: Improving Physicians' detection of patients' distress 


\begin{abstract}
Introduction. Although cancer patients are often accompanied by a relative in medical interviews, little is known about the efficacy of communication skills training programs on physicians' ability to detect cancer patients' and relatives' distress in threeperson interviews.
\end{abstract}

Purpose. First, to assess in a randomized design the impact, on physicians' ability to detect patients' and relatives' distress, of 1-hour theoretical information course followed by two communication skills training programs: a 2.5-day basic training program and the same training program consolidated by six 3-hour consolidation workshops. Second, to investigate communication factors associated with physicians' detection of patients' and relatives' distress.

Methods. Physicians, after attending the basic communication skills training program, were randomized to consolidation workshops or to a waiting list. Interviews with a cancer patient and a relative were recorded before training, after consolidation workshops for the consolidation-workshops group and about 5 months after basic training for the basic-trainingwithout-consolidation-workshops group.

Measures. Patients' and relatives' distress was recorded with the Hospital Anxiety and Depression Scale (HADS) before the interviews. Physicians rated patients' and relatives' distress on a visual analogue scale (VAS) after the interviews. Physicians' ability to detect patients' and relatives' distress was measured through computing differences between physicians' ratings of patients' and relatives' distress and patients' and relatives' self-reported 
distress. Communication skills were analyzed according to the Cancer Research Campaign Workshop Evaluation Manual.

Results. Mixed-effects modeling of physicians' detection of patients' distress showed a positive group by time effect $(P=.023)$ in favor of physicians who were randomized into the consolidation workshops. Moreover, physicians' detection of patients' distress was associated negatively with patients' self-reported distress $(P<.000)$, positively with physicians' concurrent use of assessment skills focusing on psychological information and of supportive skills $(P=.004)$, and negatively with physician's use of assessment skills focusing on general information $(P<.000)$. Mixed-effects modeling of physicians' detection of relatives' distress showed meanwhile no significant group by time effect. Physicians' detection of relatives' distress was associated negatively with relatives' self-reported distress $(P<.000)$ and with physicians using assessment skills focusing on general information $(P<$ $.017)$.

Conclusion. Results of this study show that consolidation workshops following a 2.5 day basic training program are needed in order to improve physicians' detection of patients' distress in three-person interviews. Results of this study indicate moreover the need to further improve physicians' detection of relatives' distress.

Keywords. Cancer, distress, assessment, communication skills training, relatives. 


\section{Introduction}

Detection of distress is now recognized as an important aspect of cancer patients' care [1]. This task mainly lays in the hand of physicians. Several studies have shown unfortunately that physicians often underestimate the level of distress that their patients experience [2-6]. This could be explained by the fact that physicians lack knowledge about symptoms of distress or rely on superficial signs to assess distress. Detection of distress is difficult and especially in cancer care where physical symptoms of distress may be confounded with typical side effects of cancer and its treatments. Studies have shown that distress detection was positively linked with physicians' asking questions about feelings [7, 8] and negatively with physicians inhibiting patients' cues of distress [9]. One main barrier as regards physicians' detection of patients' distress is thus patients' and physicians' lack of discussion about patients' concerns.

Patients' and physicians' attitudes that may interfere with the amount of information patients disclose about psychosocial issues have been identified [10]. Patients on the one hand may think that it is not physicians' role to deal with psychosocial issues [11]. They may think that their fears and concerns are unreasonable, that they reflect badly on their coping abilities or are a predictable result of their illness, and therefore do not disclose them to their doctors [12]. Physicians on the other hand may also feel that it is not their role to deal with patients' concerns. They may feel uncomfortable dealing with them. They may not feel trained enough in communication skills to elicit and deal with such concerns or may wait for patient to disclose them $[10,12]$. A recent study reported that the majority of patients and their physicians were willing to discuss psychosocial issues together but that many patients and physicians left the initiative of discussing these topics to the other [13]. Physicians if they want to detect patients' distress should thus directly investigate patients' concerns. 
Promoting patients' disclosure of concerns and detecting their level of distress may be more difficult when patients are accompanied by one of their relative. Twenty percent of medical interviews in cancer care however imply the presence of a relative [14]. Partners and other family members are key supports for cancer patients and a recent review reported that 10 to $50 \%$ of relatives of cancer patients experience high levels of distress [15]. Caregivers' bad adjustment has been linked moreover with patients' poor social rehabilitation [16, 17], poor treatment adherence [18], and increased emotional distress [19]. It is thus essential that distress of patients' relative be detected as well.

Recent studies have shown the interest in order to improve physicians' detection of distress of providing physicians with theoretical information about distress [20] and of coupling theoretical information with a communication skills training course [21]. An increased body of evidence exists in cancer care moreover showing that communication skills of physicians can be improved following well-designed, skill-focused, practice-oriented, and learner-centered communication skills training programs [22-25]. No study to date however has yet assessed the impact of a communication skills training program on physicians' ability to detect patients' and relatives' distress during a three-person interview (an interview where a patient is accompanied by a relative).

Therefore, our study aimed to assess, in a randomized design, the impact on physicians' ability to detect patients' and relatives' distress of two communication skills training programs: a 2.5-day basic training program and the same training program consolidated by six 3-hour consolidation workshops. Previously reported results of the impact of this training program [25] showed that physicians who had been randomized to the consolidation workshops elicited and clarified patients' concerns more often and used more 
supportive skills towards both patients and relatives. We thus hypothesized that consolidation workshops would be required in order to reach the level of improvement in physicians' assessment and supportive skills needed to allow detection of distress in three-person interviews. It is important to underline that the same question was assessed in two-person interviews: results failed to show an improvement in this context [26]. The second aim of this study was to investigate contextual, patient, relative variables and communication factors linked with physicians' detection of patients' and relatives' distress. 


\section{Methods}

\section{Study design and assessment procedure}

To be included in the study, physicians had to be specialists and to be working with cancer patients (part time or full time). The efficacy of the consolidation workshops was assessed in a study allocating physicians randomly, after a basic training program, to consolidation workshops or to a waiting list (Fig 1). The study was approved by the local ethics committee. The basic training program was spread over a 1-month period. The consolidation workshops started 2 months later for participants who were immediately assigned to the workshops. The bimonthly workshops were spread over a 3-month period. Subjects assigned to the waiting list were invited to take part in the consolidation workshops 6 months after the end of the basic training program. Detailed descriptions of the training programs have been published previously [24-26].

Please insert Figure 1

Assessments were scheduled before basic training program (T1), just after this program, and after consolidation workshops for the consolidation-workshop group and approximately 5 months after the end of basic training for the basic-training-withoutconsolidation-workshops group (T2). An interview with a cancer patient and a relative was audiotaped at each assessment time. Patients were chosen by physicians. Inclusion criteria for patients and relatives included breaking news (bad, neutral, or good), age older than 18 years, ability to speak French, absence of cognitive dysfunction, and written informed consent. Patients and relatives were different at $\mathrm{T} 1$ and $\mathrm{T} 2$. 


\section{Interview rating system}

All audiotapes were transcribed. Transcripts were assessed for their quality and then rated by trained psychologists. Rating was based on the French translation and adaptation of the Cancer Research Campaign Workshop Evaluation Manual [27]. Three-person interviews imply to state clearly to whom each utterance is addressed [28]. A new coding scale was thus created to identify whether the utterance was addressed to the patient, the relative or to both. In the statistical analyses, utterances addressed simultaneously to the patient and their relative were added both to the utterances addressed to the patient and to the utterances addressed to the relative as they could have an influence on both patients' and relatives' communication. A detailed description of the rating procedure has been published previously [24-26].

\section{Questionnaires}

Before the interviews, patients and relatives completed a sociodemographic questionnaire and the Hospital Anxiety and Depression Scale [29, 30]. Physician completed a sociodemographic and socioprofessional questionnaire. After the interviews, each physician assessed the patient's and the relative's distress on a visual analogue scale. Physicians also had to report cancer-related information about patients and information about context characteristics.

Hospital Anxiety and Depression Scale (HADS) [29]. The HADS is a four-point 14item self-report instrument assessing anxiety and depression in physically ill subjects. This scale was translated into French, and validated in a sample of cancer in-patients [30]. The use of the total score is recommended to assess psychological distress [30]. 
Physicians' ratings of patients' and relatives' Distress. Physicians rated patients' and relatives' distress on a $10 \mathrm{~cm}$ visual analogue scale (VAS) immediately after the interview. Ratings ranged from 0 (extremely distressed) to 10 (not at all distressed). Scores were inverted to enhance readability. A VAS was used as other authors have used visual analogue scales in previous studies assessing physicians' ability to detect patients' distress $[2,5]$. The VAS has moreover been shown to be a valid tool to measure patients' level of distress [3134].

\section{Statistical Analyses}

Statistical analyses of the data consisted of a comparative analysis of both groups of physicians at baseline using parametric tests and non parametric tests as appropriate ( $t$ tests and $\chi^{2}$ tests). Patients' and relatives' characteristics at baseline and after the intervention were compared using repeated measures analysis of variance (MANOVA) and $\chi^{2}$ tests as appropriate. Two new variables were computed measuring physicians' ability to detect patients' and relatives' distress. HADS scores and physicians' VAS ratings were brought up to a maximal score of 100 . The modified HADS scores were then subtracted from the modified VAS ratings. Time and group-by-time changes in these new variables called physicians' detection of patients' distress and physicians' detection of relatives' distress were then processed using repeated measures analysis of variance (MANOVA). All tests were twotailed and the alpha was set at 0.05 . Mixed-effects modeling was employed to investigate factors associated with physicians' detection of patients' and of relatives' distress. An exploratory analysis was used to identify important covariates. Factors were entered in the multivariate models only if they satisfied the inclusion criterion (ie, $P<.10$ ). A Linear MixedEffects Model with Fixed Effects was used. 


\section{Results}

\section{Physician and Patient sociodemographic Data}

The description of the recruitment procedure is summarized in Figure 1. Comparison of included and not included physicians showed no statistically significant differences for age, gender and number of years of practice. Physicians demographic and socioprofessional characteristics are described in Table 1. No statistically significant differences were found at baseline between physicians who participated to the consolidation workshops and those randomized to the waiting list.

Please insert Table 1

As displayed in Table 2, no statistically significant differences were found as regards patients' and relatives' socio-demographic characteristics, and in disease and interviews characteristics over time and between the consolidation-workshop and waiting-list groups when comparison was possible.

Please insert Table 2 


\section{Influence of attendance to the Basic Training Program and to the Consolidation Workshops on physicians' detection of patients' and of relatives' distress}

As shown in Table 3, a nearly significant MANOVA group-by-time change was noted as regards physicians' ability to detect patients' distress computed through differences between physicians' VAS ratings of patients' distress and patients' HADS scores $(P=0.052)$.

Please insert Table 3

\section{Factors associated with physicians' detection of patients' distress}

Group $(P=.92)$ and Time $(P=.61)$ although not significant were retained in the model. Patients being in current cancer treatment $(P=.069)$, patient's self-reported distress $(r=-.480$; $P<.000)$, relatives' educational level $(P=.067)$, the type of news given $(P=.012)$ and physicians' use of assessment skills focusing on psychological information $(r=.170 ; P=.072)$ and assessment skills focusing on general information $(r=-.275 ; P=.003)$ towards patients were identified as possible predictors and were retained in the multivariate model. Supportive skills although not significantly correlated with physicians' detection of patients' distress were included in the regression model. The interaction between supportive skills and assessment skills focusing on psychological information was tested as well. This was done because it has been argued that the use of supportive skills together with assessment skills focusing on psychological information could be needed to allow physicians' to better detect patients' distress [26]. Physicians' age, gender; patient's age, gender, educational level, prognosis, number of months since diagnosis; relatives' age, gender, self-reported distress, 
tie with the patient, and the type of physician-patient relationship did not satisfy the inclusion criterion (ie, $P<.10$ ).

\section{Please insert Table 4}

As shown in Table 4, mixed-effects modeling showed a negative time effect $(P=.030)$ on physicians' detection of patients' distress and a positive group by time effect $(P=.023)$ in favor of physicians who were randomized into the consolidation workshops. Moreover, physicians' detection of patients' distress was associated negatively with patients' selfreported distress $(P<.000)$, positively with physicians' concurrent use of assessment skills focusing on psychological information and of supportive skills $(P=.004)$, and negatively with physician's use of assessment skills focusing on general information $(P<.000)$.

\section{Factors associated with physicians' detection of relatives' distress}

Group $(P=.62)$ and Time $(P=.15)$ although not significant were retained in the model. Relatives' self-reported distress $(r=-.509 ; P<.000)$ and physicians' use of general assessment $(r=-.173 ; P=.068)$ were identified as possible predictors and were retained in the multivariate model. Physicians' age, gender, group allocation, assessment time, use of assessment skills focusing on psychological information and supportive skills; patients' and relatives' age, gender, educational level, patients' self-reported distress; patients' prognosis, previous and current cancer treatment and number of months since diagnosis; relatives' tie with the patient; type of news given and type of physician-patient relationship did not satisfy the inclusion criterion (ie, $P<.10$ ). 
Please insert Table 5

As shown in Table 5, physicians' detection of relatives' distress was associated negatively with relatives' self-reported distress $(P<.000)$ and with physicians using assessment skills focusing on general information $(P<.017)$. 


\section{Discussion}

This study first showed that physicians greatly differ in their ability to detect patients' and relatives' distress (as shown by the important standard deviation). As regards physicians' detection of patients' distress, it is important to note that results of the study showed a nearly significant group by time change in physicians' detection (measured through subtracting patients' HADS scores brought up to 100 from physicians' VAS ratings of patients' distress brought up to 100). This was confirmed by results of the mixed-effect modeling that showed a significant positive effect on physicians' detection of patients' distress of being randomized to the consolidation workshops compared to the basic training alone. These results contrast with previously published results of this study that failed to show an improvement in physicians' ability to better assess patients' distress in two-person interviews following the communication skills training programs [26]. This contrast could be explained by the added value of a relative's presence in an interview: patients may be more prone to express their concerns when a relative is present and relatives may provide physicians with additional information about patient's concerns.

It was also hypothesized that an improvement in physicians' use of assessment and supportive skills would lead to an improvement in physicians' ability to detect patients' distress. Results of the mixed-effect modeling as expected showed a positive effect of assessment skills focusing on psychological information on physicians' detection and confirmed previously published results of this study in two-person interviews [26]. Mixedeffect modeling also showed the detrimental effect of using assessment skills focusing on general information on physicians' detection of patients' distress: this confirms results of a study that has shown that the use of assessment skills focusing on general information inhibited patients' disclosure of concerns [35]. 
Results of this study moreover confirm the importance of supportive skills in order to detect patients' distress. However, although in two-person interviews the use of either assessment skills or of supportive skills is sufficient to allow better detection of patients' distress [26], in three-person interviews the concurrent use of both types of skills seems necessary. This may be due to the fact that, to handle three-person interviews adequately, physicians need to consider a double agenda: physicians should assess both patients' and their accompanying relatives' concerns, they should acknowledge those concerns and respond to both patients' and their relatives' concerns by supporting or informing patients and their relatives as appropriate [25]. The concurrent use of assessment and supportive skills probably facilitates the handling of this double agenda by allowing physicians to address alternatively the patient and his or her relative.

Contextual variables have been shown to influence physicians' assessment of patients' distress. In two-person interviews, physicians' detection was influenced by the type of news given by physicians (bad news) and by patient educational level [26]. In three-person interviews, results of the mixed-effects modeling showed that the phase of illness (under or not under treatment) influenced the ability to detect patients' distress. It could be hypothesized that patients under treatment have a more regular relationship with the physician that increases proximity. This proximity can have a positive impact on physicians' detection in that they have more cues of distress to detect. The influence of patients' phase of illness on physicians' detection of patients' distress may also be explained by the fact that physicians could be more attentive to cues of distress in patients under treatment. Physicians should be aware of the influence of different contextual variables that can bias their assessment of patients' distress. They should remember that distress in cancer patients is highly prevalent regardless of contextual variables. 
As regards physicians' detection of relatives' distress, no change was observed in physicians' detection following the communication skills training programs. This could be explained by the fact that although physicians start to address relatives' concerns and needs following consolidation workshops, improvements remain limited [25]. This is confirmed by results of mixed-effects modeling that showed no link between physicians' detection of relatives' distress and their use of assessment skills focusing on psychological information and of supportive skills. The level of assessment and supportive skills towards relatives may not be sufficient to allow detection of relatives' distress. This could also be explained by the fact that detecting relatives' distress is not a primary objective in physicians' agenda. Finally, as it was the case concerning physicians' detection of patients' distress, mixed-effect modeling showed the detrimental effect on physicians' detection of relatives' distress of using assessment skills focusing on general information towards them.

To our knowledge, this is the first study assessing in a randomized design the impact of two communication skills training programs (a 2.5 day basic training program and a basic training program consolidated by six three-hour workshops) on physicians' detection of cancer patients' and relatives' distress. As it was expected, a significant change was observed in physicians' detection of patients' distress following consolidation workshops. Consolidation workshops scheduled after a basic training allowed physicians to develop the communication skills needed to improve their detection of patients' distress. Results in threeperson interviews show the added value of the presence of a relative in interviews with cancer patients as it helps physicians improve their detection of patients' distress. This study shows meanwhile that improvements need to be made as regards physicians' communication with relatives in order to generate a more accurate detection of relatives' distress. Practically, it can be argued that detecting relatives' distress is not one of the main aim of a medical interview 
and that physicians do not need to devote time to this matter. Relatives however are often patients' primary caregivers and their own distress may be detrimental to patients' adjustment [16-19]. It could thus also be argued that physician need to devote time to the assessment of relatives' distress in order to improve care. 


\section{Contributors}

Darius Razavi, Nicole Delvaux and Christine Reynaert conceived the study, wrote the protocol, obtained funding, and supervised data collection and analysis. Darius Razavi, Nicole Delvaux and Serge Marchal conducted the training courses. Serge Marchal supervised data collection. Jacques Boniver, Jean Klastersky and Pierre Scalliet participated to the writing of the protocol and obtained funding. Anne-Marie Etienne supervised data collection. Isabelle Merckaert contributed to data collection and to the rating of the interviews, participated in the data analysis, and wrote the first drafts of the report. Yves Libert contributed to data collection, coordinated day-to-day management of the project, participated in preparation of data analysis, and contributed to the writing of the first drafts of the report. Jean-Louis Slachmuylder designed the database and contributed to data collection and final analysis. All the investigators contributed to the writing of the final report.

\section{Conflict of interest statement}

None declared. 


\section{Acknowledgements}

This research program was supported by the « Fonds National de la Recherche Scientifique Section Télévie» of Belgium, by the «Fonds d'Encouragement à la Recherche de l'Université Libre de Bruxelles »(Brussels - Belgium) and by the C.A.M., training and research group (Brussels - Belgium). We are grateful to all the physicians and patients who participated in the study. 


\section{References}

1. National Comprehensive Cancer Network, N., Distress management: Clinical Practice Guidelines, in JNCCN. 2003. p. 344-374.

2. Ford, S., L. Fallowfield, and S. Lewis, Can oncologists detect distress in their out-patients and how satisfied are they with their performance during bad news consultations? $\mathrm{Br} \mathrm{J}$ Cancer, 1994. 70(4): p. 767-70.

3. Sollner, W., et al., How successful are oncologists in identifying patient distress, perceived social support, and need for psychosocial counselling? Br J Cancer, 2001. 84(2): p. 179-85.

4. Newell, S., et al., How well do medical oncologists' perceptions reflect their patients' reported physical and psychosocial problems? Data from a survey of five oncologists. Cancer, 1998. 83(8): p. 1640-51.

5. Fallowfield, L., et al., Psychiatric morbidity and its recognition by doctors in patients with cancer. Br J Cancer, 2001. 84(8): p. 1011-5.

6. Passik, S.D., et al., Oncologists' recognition of depression in their patients with cancer. J Clin Oncol, 1998. 16(4): p. 1594-600.

7. Carney, P.A., et al., How physician communication influences recognition of depression in primary care. J Fam Pract, 1999. 48(12): p. 958-64.

8. Watts, S.C., et al., Mental health in older adult recipients of primary care services: is depression the key issue? Identification, treatment and the general practitioner. Int J Geriatr Psychiatry, 2002. 17(5): p. 427-37.

9. Davenport, S., D. Goldberg, and T. Millar, How psychiatric disorders are missed during medical consultations. Lancet, 1987. 2(8556): p. 439-41.

10. Ryan, H., et al., How to recognize and manage psychological distress in cancer patients. Eur J Cancer Care (Engl), 2005. 14(1): p. 7-15.

11. Cape, J. and Y. McCulloch, Patients' reasons for not presenting emotional problems in general practice consultations. Br J Gen Pract, 1999. 49(448): p. 875-9. 
12. Docherty, J.P., Barriers to the diagnosis of depression in primary care. J Clin Psychiatry, 1997. 58 Suppl 1: p. 5-10.

13. Detmar, S.B., et al., How are you feeling? Who wants to know? Patients' and oncologists' preferences for discussing health-related quality-of-life issues. J Clin Oncol, 2000. 18(18): p. 3295-301.

14. Beisecker, A.E. and W.P. Moore, Oncologists' perceptions of the effects of cancer patients' companions on physician-patient interactions. Journal of Psychosocial Oncology, 1994. 12(1/2): p. 23-39.

15. Pitceathly, C. and P. Maguire, The psychological impact of cancer on patients' partners and other key relatives: a review. Eur J Cancer, 2003. 39(11): p. 1517-24.

16. Carnwath, T.C. and D.A. Johnson, Psychiatric morbidity among spouses of patients with stroke. BMJ, 1987. 294: p. 409-411.

17. Northouse, L.L., et al., Couples' patterns of adjustment to colon cancer. Soc Sci Med, 2000. 50(2): p. 271-84.

18. Evans, R.L., et al., Family interaction and treatment adherence after stroke. Arch Phys Med Rehabil, 1987. 68: p. 513-517.

19. Hodges, L.J., G.M. Humphris, and G. Macfarlane, A meta-analytic investigation of the relationship between the psychological distress of cancer patients and their carers. Soc Sci Med, 2005. 60: p. 1-12.

20. Passik, S.D., et al., Oncology staff recognition of depressive symptoms on videotaped interviews of depressed cancer patients: implications for designing a training program. $\mathbf{J}$ Pain Symptom Manage, 2000. 19(5): p. 329-38.

21. Roter, D.L., et al., Improving Physicians Interviewing Skills and Reducing Patients Emotional Distress - a Randomized Clinical-Trial. Archives of Internal Medicine, 1995. 155(17): p. 1877-1884.

22. Fallowfield, L., et al., Efficacy of a Cancer Research UK communication skills training model for oncologists: A randomised controlled trial. Lancet, 2002. 359(9307): p. 650-656. 
23. Jenkins, V. and L. Fallowfield, Can communication skills training alter physicians' beliefs and behavior in clinics? Journal of Clinical Oncology, 2002. 20(3): p. 765-769.

24. Razavi, D., et al., How to optimize physicians' communication skills in cancer care: results of a randomized study assessing the usefulness of posttraining consolidation workshops. J Clin Oncol, 2003. 21(16): p. 3141-9.

25. Delvaux, N., et al., Physicians' communication with a cancer patient and a relative: $a$ randomized study assessing the efficacy of consolidation workshops. Cancer, 2005. 103(11): p. 2397-2411.

26. Merckaert, I., et al., Factors influencing physicians' detection of cancer patient distress: Can a communication skills training program improve physicians' detection? Cancer, 2005: p. In press.

27. Booth, C. and P. Maguire, Development of a rating system to assess interaction between cancer patients and health professionals. 1991, London: Report to Cancer Research Campaign. 37.

28. Adelman, R.D., M.G. Greene, and R. Charon, The Physician-Elderly Patient-Companion Triad in the Medical Encounter - the Development of a Conceptual-Framework and Research Agenda. Gerontologist, 1987. 27(6): p. 729-734.

29.Zigmond, A.S. and R.P. Snaith, The hospital anxiety and depression scale. Acta Psychiatr Scand, 1983. 67(6): p. 361-70.

30. Razavi, D., et al., Screening for adjustment disorders and major depressive disorders in cancer in-patients. Br J Psychiatry, 1990. 156: p. 79-83.

31. Lees, N. and M. Lloyd-Williams, Assessing depression in palliative care patients using the visual analogue scale: a pilot study. Eur J Cancer Care (Engl), 1999. 8(4): p. 220-3.

32. Payne, D.K., et al., Screening for anxiety and depression in women with breast cancer. Psychiatry and medical oncology gear up for managed care. Psychosomatics, 1999. 40(1): p. 64-9. 
33. Donovan, K.A., et al., Psychometric properties and correlates of distress thermometer scores. Psychooncology, 2004. 13(1): p. S16-S16 Suppl. S.

34. Jacobsen, P.B., et al., Multi-center study of the utility of the Distress Thermometer as a screening instrument in a general cancer population. Psychooncology, 2004. 13(1): p. S42S43 Suppl. S.

35. Maguire, P., et al., Helping cancer patients disclose their concerns. Eur J Cancer, 1996. 32A(1): p. 78-81. 
Figure 1. Study design, with timing of evaluations and interventions [34] 


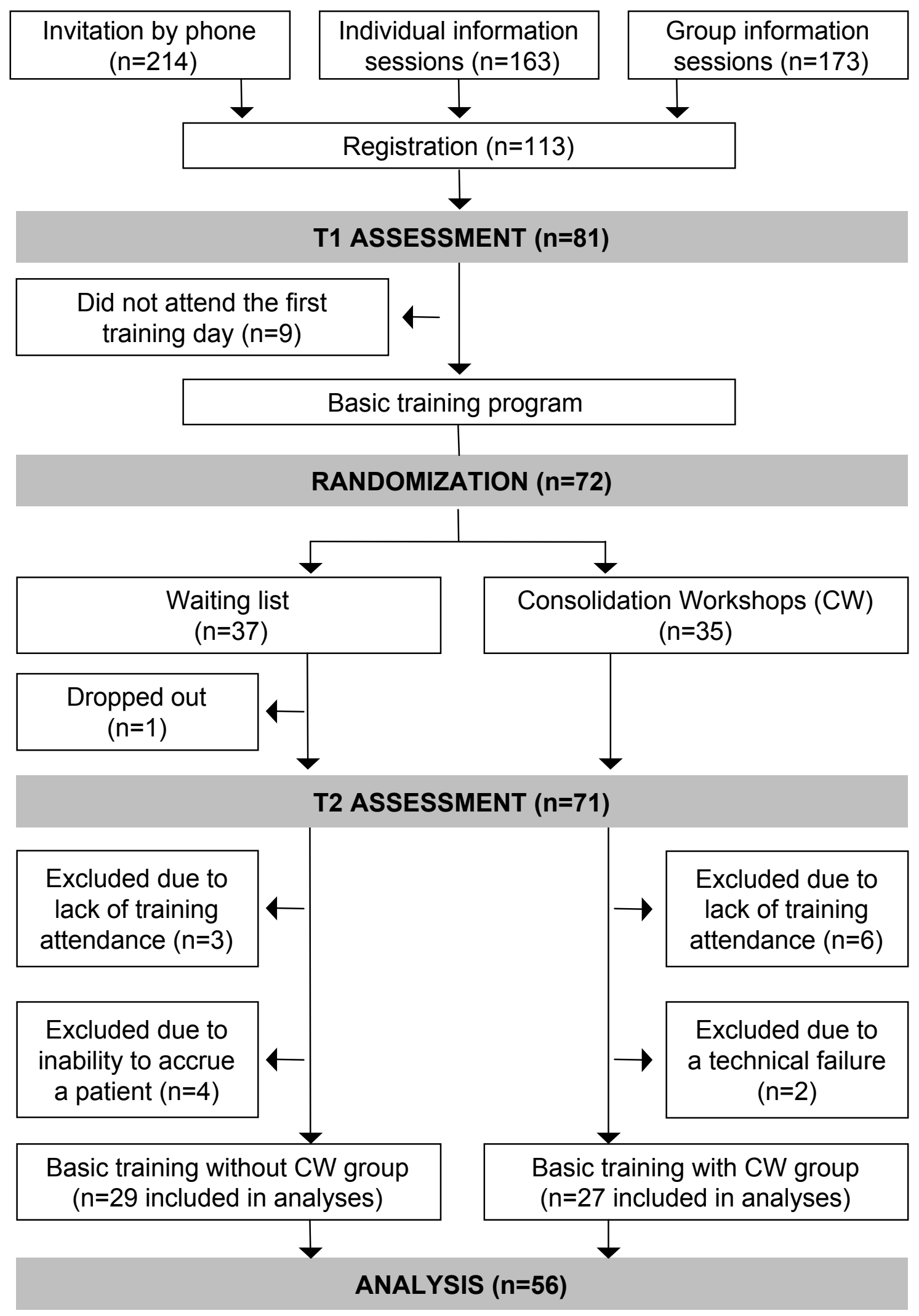


Table 1. Physicians' sociodemographic and professional characteristics

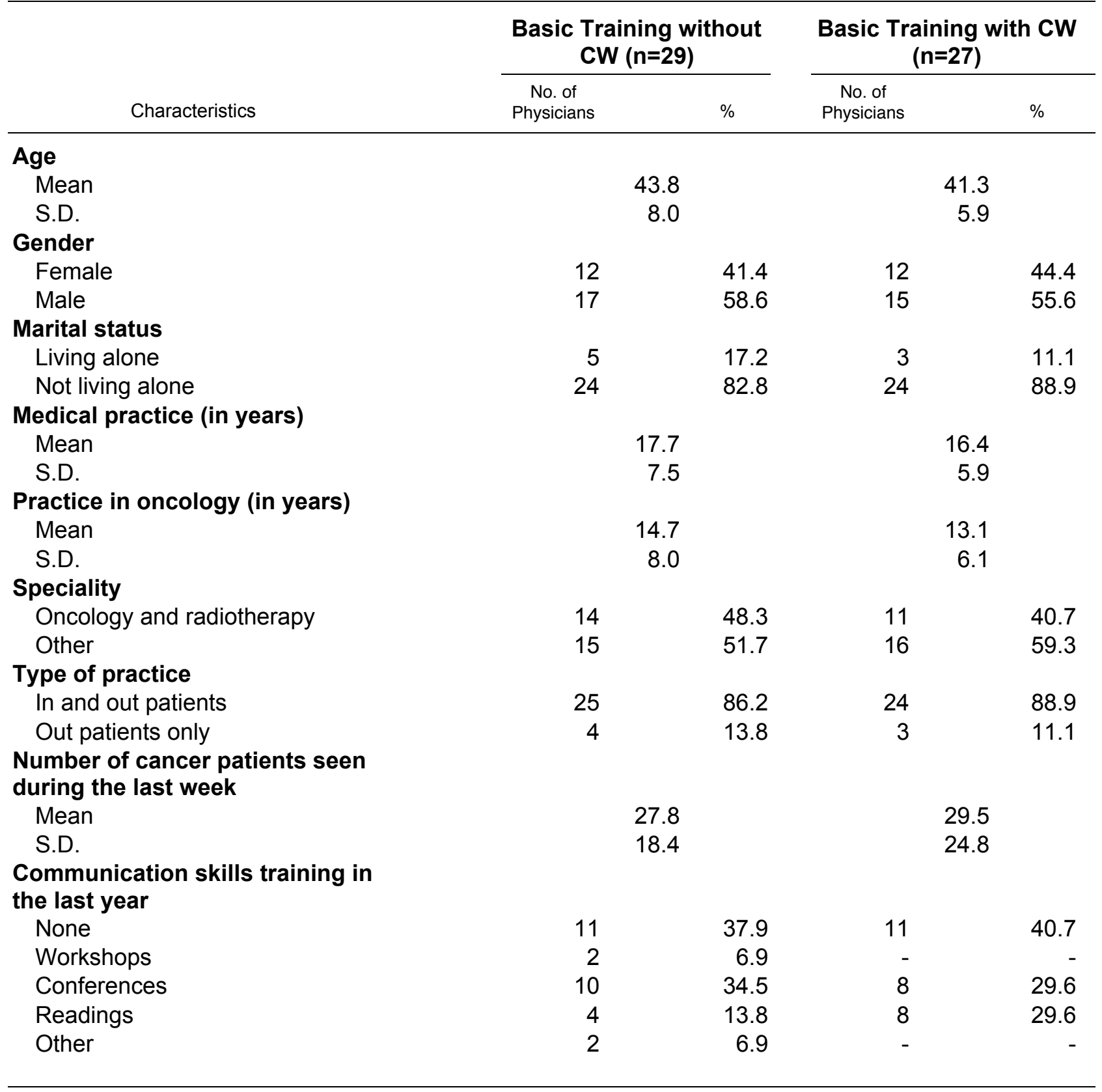




\begin{tabular}{|c|c|c|c|c|c|c|c|c|}
\hline \multirow[b]{3}{*}{ Characteristics } & \multicolumn{4}{|c|}{ Basic Training without CW $(n=29)$} & \multicolumn{4}{|c|}{ Basic Training with $\mathrm{CW}(\mathrm{n}=27)$} \\
\hline & \multicolumn{2}{|c|}{ At baseline } & \multicolumn{2}{|c|}{$\begin{array}{c}5 \text { months after Basic } \\
\text { Training }\end{array}$} & \multicolumn{2}{|c|}{ At baseline } & \multicolumn{2}{|c|}{ After CW } \\
\hline & $\begin{array}{l}\text { No. of } \\
\text { Patients }\end{array}$ & $\%$ & $\begin{array}{l}\text { No. of } \\
\text { Patients }\end{array}$ & $\%$ & $\begin{array}{l}\text { No. of } \\
\text { Patients }\end{array}$ & $\%$ & $\begin{array}{l}\text { No. of } \\
\text { Patients }\end{array}$ & $\%$ \\
\hline \multicolumn{9}{|c|}{ Patients' sociodemographic characteristics } \\
\hline \multicolumn{9}{|l|}{ Age } \\
\hline Mean & \multicolumn{2}{|c|}{61.0} & \multicolumn{2}{|c|}{62.9} & \multicolumn{2}{|c|}{60.8} & \multicolumn{2}{|c|}{60.1} \\
\hline SD & \multicolumn{2}{|c|}{11.5} & \multicolumn{2}{|c|}{10.6} & \multicolumn{2}{|c|}{11.5} & & \\
\hline Gender & & & & & & & & \\
\hline Male & 13 & 44.8 & 7 & 24.1 & 11 & 40.7 & 11 & 40.7 \\
\hline Female & 16 & 55.2 & 22 & 75.9 & 16 & 59.3 & 16 & 59.3 \\
\hline Educational level & & & & & & & & \\
\hline Junior high school or less & 15 & 51.7 & 11 & 37.9 & 10 & 37.0 & 12 & 44.4 \\
\hline High school graduate & 6 & 20.7 & 5 & 17.2 & 6 & 22.2 & 7 & 25.9 \\
\hline College or university graduation & 8 & 27.6 & 13 & 44.8 & 11 & 40.7 & 8 & 13.0 \\
\hline Karnofsky score & & & & & & & & \\
\hline 80 or more & 26 & 89.7 & 23 & 79.3 & 20 & 74.1 & 18 & 66.7 \\
\hline Less than 80 & 3 & 10.3 & 6 & 20.7 & 7 & 25.9 & 9 & 33.3 \\
\hline $\begin{array}{l}\text { Relatives' sociodemographic } \\
\text { characteristics }\end{array}$ & & & & & & & & \\
\hline Age & & & & & & & & \\
\hline Mean & & & & & & & & \\
\hline SD & & & & & & & & \\
\hline Gender & & & & & & & & \\
\hline Male & 13 & 44.8 & 17 & 58.6 & 13 & 48.1 & 17 & 63.0 \\
\hline Female & 16 & 55.2 & 12 & 41.4 & 14 & 51.9 & 10 & 37.0 \\
\hline Educational level & & & & & & & & \\
\hline Junior high school or less & 25 & 86.2 & 25 & 86.2 & 22 & 81.5 & 20 & 74.1 \\
\hline High school graduate & 4 & 13.8 & 1 & 3.4 & 2 & 7.4 & 3 & 11.1 \\
\hline College or university graduation & 0 & 0.0 & 3 & 10.3 & 3 & 11.1 & 4 & 14.8 \\
\hline Tie with the patient & & & & & & & & \\
\hline Partner & 25 & 86.2 & 25 & 86.2 & 21 & 77.8 & 20 & 74.1 \\
\hline Parent, child or sibling & 4 & 13.8 & 2 & 6.9 & 3 & 11.1 & 3 & 11.1 \\
\hline Friend or other & 0 & 0.0 & 2 & 6.9 & 3 & 11.1 & 4 & 14.8 \\
\hline Disease characteristics & & & & & & & & \\
\hline Months since diagnosis & & & & & & & & \\
\hline Mean & & & & & & & & \\
\hline SD & & & & & & & & \\
\hline Prognosis & & & & & & & & \\
\hline Less than 6 months & 1 & 3.4 & 4 & 13.8 & 2 & 7.4 & 1 & 3.7 \\
\hline Six months till a year & 3 & 10.3 & 6 & 20.7 & 9 & 33.3 & 9 & 33.3 \\
\hline One year or more & 25 & 86.2 & 19 & 65.5 & 16 & 59.3 & 17 & 63.0 \\
\hline Current cancer treatment & & & & & & & & \\
\hline Yes & 19 & 65.5 & 21 & 72.4 & 20 & 74.1 & 17 & 63.0 \\
\hline No & 10 & 34.5 & 8 & 27.6 & 7 & 25.9 & 10 & 37.0 \\
\hline Previous cancer treament & & & & & & & & \\
\hline Yes & 12 & 41.4 & 17 & 58.6 & 14 & 51.9 & 16 & 59.3 \\
\hline No & 17 & 58.6 & 12 & 41.4 & 13 & 48.1 & 11 & 40.7 \\
\hline Interviews characteristics & & & & & & & & \\
\hline Type of news & & & & & & & & \\
\hline Neutral & 8 & 27.6 & 11 & 37.9 & 10 & 37.0 & 13 & 48.1 \\
\hline Good & 9 & 31.0 & 13 & 44.8 & 8 & 29.6 & 8 & 29.6 \\
\hline Bad & 12 & 41.4 & 5 & 17.2 & 9 & 33.3 & 6 & 22.2 \\
\hline Type of information & & & & & & & & \\
\hline Diagnosis focused & 15 & 51.7 & 9 & 31.0 & 10 & 37.0 & 13 & 48.1 \\
\hline Treatment and prognosis focused & 14 & 48.3 & 20 & 69.0 & 17 & 63.0 & 14 & 51.9 \\
\hline Type of physician-patient relationship & & & & & & & & \\
\hline First encounter & 3 & 10.3 & 3 & 10.3 & 5 & 18.5 & 3 & 11.1 \\
\hline Seen previously & 26 & 89.7 & 26 & 89.7 & 22 & 81.5 & 24 & 88.9 \\
\hline
\end{tabular}


Table 3. Changes in Physicians' Ratings of Patients' Distress (VAS), in Patients' self-reported Distress (HADS total score) and in Physicians' Detection of Patients' Distress

\begin{tabular}{|c|c|c|c|c|c|c|c|c|c|c|c|c|}
\hline & \multicolumn{4}{|c|}{$\begin{array}{l}\text { Basic training without CW } \\
\qquad(n=29)\end{array}$} & \multicolumn{4}{|c|}{$\begin{array}{l}\text { Basic training with } \mathrm{CW} \\
\qquad(\mathrm{n}=27)\end{array}$} & \multicolumn{4}{|c|}{ MANOVA } \\
\hline & \multicolumn{2}{|c|}{ At baseline } & \multicolumn{2}{|c|}{$\begin{array}{l}5 \text { Months After } \\
\text { Basic Training }\end{array}$} & \multicolumn{2}{|c|}{ At baseline } & \multicolumn{2}{|c|}{ After CW } & \multicolumn{2}{|c|}{ Time } & \multicolumn{2}{|c|}{$\begin{array}{l}\text { Group by } \\
\text { Time }\end{array}$} \\
\hline & Mean & SD & Mean & SD & Mean & SD & Mean & SD & $F_{1,56}$ & $P$ & $F_{1,56}$ & $P$ \\
\hline \multicolumn{13}{|l|}{ Patients } \\
\hline $\begin{array}{l}\text { Physicians' Ratings of Patients' } \\
\text { distress (VAS) }\end{array}$ & 3.9 & 2.6 & 3.3 & 2.1 & 3.6 & 2.0 & 4.4 & 1.8 & .05 & .819 & 2.89 & .095 \\
\hline $\begin{array}{l}\text { Patients' self-reported Distress } \\
\text { (HADS Total Score) }\end{array}$ & 12.6 & 8.3 & 12.9 & 7.5 & 15.1 & 8.3 & 13.4 & 8.0 & .20 & .657 & .42 & .518 \\
\hline $\begin{array}{l}\text { Physicians' detection of patients' } \\
\text { distress* }\end{array}$ & 9.2 & 23.0 & 2.4 & 21.4 & 0.3 & 23.9 & 12.2 & 22.3 & .29 & .590 & 3.93 & .052 \\
\hline \multicolumn{13}{|l|}{ Relatives } \\
\hline $\begin{array}{l}\text { Physicians' Ratings of Relatives' } \\
\text { distress (VAS) }\end{array}$ & 3.5 & 2.7 & 3.3 & 2.0 & 3.5 & 2.0 & 3.8 & 1.8 & .06 & .801 & .53 & .469 \\
\hline $\begin{array}{l}\text { Relatives' self-reported Distress } \\
\text { (HADS Total Score) }\end{array}$ & 15.3 & 7.7 & 12.1 & 5.8 & 14.6 & 7.5 & 12.8 & 6.2 & 3.38 & .071 & .26 & .613 \\
\hline $\begin{array}{l}\text { Physicians' detection of Relatives' } \\
\text { distress* }\end{array}$ & -1.5 & 22.8 & 4.3 & 22.3 & -0.2 & 29.7 & 7.6 & 23.1 & 2.47 & .122 & .06 & .814 \\
\hline
\end{tabular}

Abbreviations: CW, consolidation workshops; MANOVA, repeated measures of variance; SD, standard deviation.

* Computed through a difference between physicians' ratings of patients' distress (VAS) and patients' self-reported distress (HADS) 
Table 4. Mixed-Effects Model for Physicians' detection of patients' distress over Time and between Groups (fixed effects)

\begin{tabular}{|c|c|c|c|c|}
\hline Variables in Order Entered into Model & $\begin{array}{l}\text { Estimates of } \\
\text { Effects }\end{array}$ & $\begin{array}{l}\text { Standard } \\
\text { Error }\end{array}$ & $95 \% \mathrm{Cl}$ & $P$ \\
\hline \multicolumn{5}{|l|}{ Physicians' detection of patients' distress* } \\
\hline Intercept & 43.93 & 5.53 & 32.94 to 54.91 & $<.000$ \\
\hline \multicolumn{5}{|l|}{ Group } \\
\hline BT with CW group vs BT without CW group & -9.99 & 5.12 & -20.26 to & .056 \\
\hline \multicolumn{5}{|l|}{ Time } \\
\hline 6 months after baseline vs baseline & -10.35 & 4.71 & -19.69 to -1.01 & .030 \\
\hline Group X Time & 15.87 & 6.89 & 2.20 to 29.53 & .023 \\
\hline \multicolumn{5}{|l|}{ Current cancer treatment } \\
\hline No vs Yes & -9.83 & 3.37 & -16.50 to -3.15 & .004 \\
\hline Patients' self-reported Distress ${ }^{\S}$ & -1.35 & .21 & -1.78 to -.93 & $<.000$ \\
\hline $\begin{array}{l}\text { Physicians' assessment skills focusing on } \\
\text { psychological information } X \text { supportive } \\
\text { skills }\end{array}$ & .62 & .21 & .20 to 1.04 & .004 \\
\hline $\begin{array}{l}\text { Physicians' assessment skills focusing on } \\
\text { general information }\end{array}$ & -.74 & .16 & -1.05 to -.43 & $<.000$ \\
\hline
\end{tabular}

Abbreviations: CW, Consolidation-workshops; BT, Basic-training.

* Computed through a difference between physicians' ratings of patients' distress (VAS) and patients' self-reported distress (HADS)

$\S$ HADS Total Score 
Table 5. Mixed-Effects Model for Physicians' detection of relatives' distress over Time and between Groups (fixed effects)

Variables in Order Entered into Model

Physicians' detection of relatives' distress*

Intercept

Group

BT with CW group vs BT without CW group

Time

6 months after baseline vs baseline

\section{Group X Time}

Relatives' self-reported Distress ${ }^{\S}$

Physicians' assessment skills focusing on general information
Estimates of Effects

34.95

7.06

20.92 to 48.97

$<.000$

$-2.54$

6.04

-14.65 to 9.57

.676

$-1.08$

7.04

5.57

7.96

-12.12 to 9.96

.847

$-1.86$

.29

-8.74 to 22.82

.378

$-.41$

.17

-2.45 to -1.28

$<.000$

-.74 to -.07

.017

Abbreviations: CW, Consolidation-workshops; BT, Basic-training; HADS, Hospital Anxiety and Depression Scale.

* Computed through a difference between physicians' ratings of relatives' distress (VAS) and relatives' self-reported distress (HADS)

$\S$ HADS Total Score 